\title{
Past and Future Challenges in Creating Emotionally-Engaging Real-Time Digital Actors in Videogames
}

\author{
Casey Hudson \\ BioWare Edmonton, Alberta, Canada \\ http://www. bioware.com
}

\begin{abstract}
Evolving beyond their origins as a novel pastime, videogames have developed into a medium with tremendous power to entertain and engage players through emotionally powerful interaction. These emotional connections are often powered by the quality of the digital actors that inhabit game worlds and bring them to life. But as technologies for creating lifelike characters escalate, so do the challenges of the creation process. This discussion examines methods used by cutting-edge games to create deeply compelling digital actors, and explores future challenges and solutions that will help videogames unlock the full potential of emotionally engaging human interaction.
\end{abstract}

